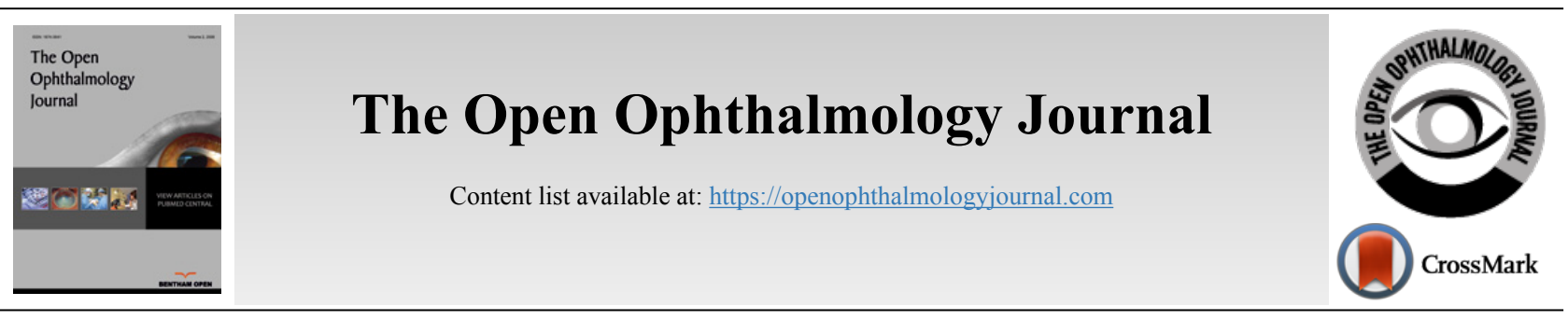

RESEARCH ARTICLE

\title{
Knowledge and Awareness of the Coronavirus Disease and Perceptions Towards Ophthalmic Practice Among Ophthalmologists
}

\author{
Yazan Gammoh ${ }^{1, *(\mathbb{D})}$ \\ ${ }^{\prime}$ Department of Optometry Science, Faculty of Allied Medical Sciences, Al-Ahliyya Amman University, Amman, Jordan
}

\begin{abstract}
:
Objective:

To investigate the level of awareness of ophthalmologists towards COVID-19 and their perceptions towards infection control in ophthalmic practice.

Methods:

A web-based survey was conducted using Google Forms during the month of December 2020. All ophthalmologists practicing in Sudan were invited to participate in the study. Participants who did not agree to the terms of the electronic consent form presented at the beginning of the questionnaire as well as those who did not complete the survey, were excluded from the analysis. Knowledge of causes, symptoms, and methods of transmission of COVID-19; ophthalmologists' attitudes and perceptions towards COVID-19 and clinical practice, including contact lens practice, were assessed using a set of 26 multiple-choice close-ended questions.

Results:

Of the 307 participants, $77.4 \%$ were in the age range $30-40$ years and $73 \%$ were contact lens practitioners. While $96.1 \%$ acknowledged the scientific name of COVID-19, 46.9\% were aware of its cause. Ophthalmologists aged 40-50 years were more likely to agree that air-puffing tonometer risks infection spread (OR $1.62,95 \%$ CI: $0.27-9.70, \mathrm{p}<0.01$ ). Ophthalmologists aged $30-40$ years were more likely to agree that a slit lamp shield would reduce infection risk (OR $1.52,95 \%$ CI: $0.33-6.96, p<0.01)$. Contact lens practitioners were more likely to perceive that frequent replacement contact lens use can increase the infection spread (OR 2.64, 95\% CI: 1.17-5.94, p $<0.01$ ).

\section{Conclusion:}

Ophthalmologists in Sudan demonstrated a mixed level of knowledge of the causes, symptoms, and modes of transmission of COVID-19. While the majority were able to identify the protective measures generally required by medical practitioners and patients, there was a limited level of knowledge regarding protective measures specific to ophthalmic practices, especially when dealing with contact lenses. Official national guidelines about safe ophthalmic service provision during the COVID-19 pandemic are recommended.
\end{abstract}

Keywords: COVID-19, Contact lens, Ophthalmology, Infection control, Coronavirus, SARS-CoV-2.

\begin{tabular}{|l|c|c|c|}
\hline Article History & Received: April 28, 2021 & Revised: July 15, 2021 & Accepted: July 28, 2021 \\
\hline
\end{tabular}

\section{INTRODUCTION}

Severe acute respiratory syndrome coronavirus 2 (SARSCoV-2) is considered the third novel coronavirus in 17 years $[1,2]$. Since it was first reported in Wuhan, China, the virus had spread globally, with the World Health Organization (WHO) declaring it as a Public Health Emergency of International Concern on 30 January 2020 and a pandemic on 11 March 2020 [3]. SARS-CoV-2 is a source of major challen-

\footnotetext{
* Address correspondence to this author at the Department of Optometry Science, Faculty of Allied Medical Sciences, Al-Ahliyya Amman University, Amman, P.O. Box 121, 19328, Jordan; Tel: +962797931373;

E-mail: gammohyazan@yahoo.com
}

ges for the prevention and treatment of its infection due to multiple potential hosts and high transmissibility and infectivity rate $[4,5]$. There are various methods of the COVID-19 human-to-human spread, including direct contact and airborne droplets. Several routes of exposure have been reported, including respiratory, ocular, blood and saliva exposure $[2,6]$. Ocular involvement is of particular interest to ophthalmologists as the polymerase chain reaction examination on tears from SARS-CoV infection was reported positive [2]. The aforementioned facts put ophthalmologists under high physical and psychological stress for their role in disease transmission as well as prevention [2, 7]. 
WHO and Center for Disease Control and Prevention's (CDC) guidelines for healthcare providers advocate the use of Personal Protection Equipment (PPE) such as full protection gowns, gloves, eye protection, facial protection such as fullface shield, and face mask $[8,9]$. In addition, healthcare providers were advised not to directly touch any mucosal membranes, including nose, mouth, or eyes [2, 10]. Other infection preventive and control (IPC) measures include the following: covering coughs and sneezes with tissues that are then safely disposed of; regular hand washing with soap or disinfection with hand sanitizer containing at least $60 \%$ alcohol, avoidance of contact with infected people, and maintaining safe social distances [11].

As a result of the spread of the virus, governments across the world, including the Sudanese government, have initiated several measures which severely restrict social interactions and travel [12]. Nevertheless, with the ease of restrictions and opening of ophthalmic practices, there is a need to understand the knowledge and awareness of ophthalmologists regarding the COVID-19 as they are among the healthcare providers in concern, partially because of ocular transmission of the disease through close contact with patients' ocular secretions including conjunctival, aerosol, and tear secretions or contaminated surfaces. Not to mention the daily high patient volume waiting lists in the clinics, particularly after the relatively long-duration closure [13]. In addition, various devices used in an ophthalmic setting such as slit lamps, air-puff tonometers and imaging devices are suspected COVID-19 spread weapons [14, 15]. Also, despite the low infection risk reported among contact lens wearers, there is a risk that could be attributed to the fact that contact lens users frequently touch their eyes during contact lens application or removal [12].

Given the multiple factors of virus infection and spread among ophthalmologists and patients in ophthalmology clinics, the study aimed to investigate the level of knowledge and awareness of ophthalmologists towards COVID-19 and their perceptions towards infection control in ophthalmic practice with a special interest in contact lens practice.

\section{MATERIALS AND METHODS}

\subsection{Study Design and Population}

A web-based, cross-sectional study was conducted during December of the year 2020 using an online survey hosted through Google Forms and distributed to ophthalmologists practicing in Sudan. A sample size of 307 was deemed to be representative of a population of 450 ophthalmologists [16], assuming a $95 \%$ confidence interval level and a $\pm 5 \%$ margin of error.

All ophthalmologists who are practicing in Sudan were eligible to participate in the study. Participants who did not agree to the terms of the electronic consent form presented at the beginning of the questionnaire and those who did not complete the survey were excluded from the analysis.

\subsection{Data Collection Tools}

The questionnaire was developed based on the content of the World Health Organization (WHO) online course on emerging respiratory viruses, including COVID-19 [17]; and pertinent literature on contact lens practice during the COVID-19 pandemic $[12,18]$. The questionnaire was designed as a set of 26 multiple-choice close-ended questions that covered the following: sociodemographic characteristics of participants; knowledge of causes, symptoms, signs, and methods of transmission of COVID-19; ophthalmologists' attitudes and perceptions towards COVID-19 and clinical practice, including contact lens practice in ophthalmology clinics. The questionnaire was reviewed by a group of 10 expert ophthalmologists and the content was evaluated for clarity, relevance and feasibility. The edited version of the questionnaire was piloted on a sample of 35 ophthalmologists to assess its reliability and a Cronbach's alpha value of 0.8 was obtained. After addressing redundant questions, the final version was distributed and the responses of the pilot study were not included in the data analysis.

\subsection{Data Analysis and Ethical Consideration}

Data were exported from Google Forms and entered into Microsoft Excel Spreadsheets with data analysis performed using the SPSS software version 25 (IBM Corporation, Armonk, NY, USA). Numbers and percentages were calculated to describe categorical and nominal data. A two-tailed t-test analysis within subjects was conducted. The ODDs ratios and 95\% Confidence Interval levels were calculated using multinomial logistic regression. A P value lower than 0.01 was considered as statistically significant.

The study was conducted as per the tenets of the Declaration of Helsinki, and the Checklist for Reporting Results of Internet E-Surveys (CHERRIES) was followed [19]. Participants' personal information was anonymous and participation in the online survey was voluntary. Participants were free to withdraw from the study at any point, as stated in the electronic consent form that the participants had to read and agree to prior to filling the questionnaire. Ethical approval (approval number: AAU-1/6/2019-2020) was obtained from the Ethical Committee of the Faculty of Allied Medical Sciences at Al-Ahliyya Amman University.

\section{RESULTS}

\subsection{Participants Demographics}

A total of 307 (169 males and 138 females) ophthalmologists participated in the study; all data collected were included in the analysis. The majority of the participants were in the age range $30-40$ years $(77.4 \%)$. Only 7 participants were above the age of 60 . While $88.6 \%$ of the ophthalmologists hold a Bachelor's degree, only $7.8 \%$ and $3.6 \%$ hold Master's and $\mathrm{Ph} . \mathrm{D}$. degrees, respectively. Contact lens fitting was reported by $73 \%$ of the sample. Unsurprisingly, $96.1 \%$ of the participants acknowledged the scientific name of the 2019 novel coronavirus. However, only $46.9 \%$ recognized the source of the emergence of the SARS-CoV-2.

3.2. Level of Awareness of COVID-19 Mode of Transmission, Symptoms, Approaches to Increase Immunity, and Protection Measures among Ophthalmologists in Sudan

All the participants agreed that direct contact with a 
COVID-19 patient is a major mode of virus transmission, while $99.3 \%$ and $99 \%$ agreed that a sneeze splash and touching a contaminated surface, respectively, are modes of transmission of the SARS-CoV-2. On the other hand, $40.7 \%$ disagreed or were not aware that animals could spread the virus.

Regarding the awareness of the symptoms of COVID-19, fever, coughing, and shortness of breath were acknowledged by $99 \%, 97 \%$, and $96 \%$ of the participants, respectively. Meanwhile, headache, throat congestion, and nasal congestion were acknowledged by $94 \%, 91 \%$ and $89 \%$ of the ophthalmologists. Nevertheless, $51.5 \%$ and $41.7 \%$ of the sample were not sure or disagreed that diarrhea and vomiting were a symptom of COVID-19, respectively.

Almost all participants were aware of approaches to increase immunity, including regular exercise (95\%), healthy food intake (94\%), sufficient sleeping (92\%), vitamin C intake $(84 \%)$, and smoking cessation $(81 \%)$. However, many were not sure of the roles of reducing stress $(33 \%)$, vitamin D (42\%) or vitamin $\mathrm{E}(47 \%)$ intake in boosting immunity against the virus.

\subsection{Health and Safety Measures Practiced by Ophthalmo- logists in Sudan}

Hand cleaning by either washing with soap and water or using a disinfectant was reported by $45.3 \%$, and $52.4 \%$, of the ophthalmologists, respectively. Meanwhile, $48.5 \%$ of the participants use a tissue when sneezing, with only $46.3 \%$ reporting immediate and safe disposal of the tissue. On the other hand, $42.7 \%$ of the sample reported that they used the top of the arm as a method of containing their sneeze in the absence of tissue. Face masks were not worn in the workplace by $49.5 \%$ of the sample.

In terms of the health and safety precautions that ophthalmologists in Sudan took after announcing the recording of COVID-19 cases in Sudan and prior to the lockdown that was imposed by the government, general hygiene was maintained by $99 \%$ of the practitioners, with $73.3 \%$ reported sleeping for at least 8 hours per night. Only $16.9 \%$ reported that they stopped attending work. All of them were females who were either pregnant or had children. In terms of travel, $52.8 \%$ avoided traveling to areas where the infection was reported, $48.5 \%$ reported that they decided not to travel by airplanes, $47.2 \%$ avoided using public transport, while $41.7 \%$ of the sample avoided using taxis.

\subsection{Perceptions of Ophthalmologists Towards Potential Sources of COVID-19 Infection in the Workplace and the Role of Contact Lenses in the Infection Cycle}

Using a non-contact tonometer operated by producing a puff of air was thought to increase the risk of spreading the infection by $31.3 \%$ of the sample. On the other hand, $65.5 \%$ of ophthalmologists agreed that using a shield fitted on the slit lamp to act as a barrier between the patient and practitioner would reduce the risk of infection. Meanwhile, $44 \%$ of the participants believed that appointments should be postponed until the country is announced disease-free.
Most of the participants (94.5\%) said that hands should be washed both before and after checking the eyes or contact lenses evaluation. Regarding the role of contact lens wear modality in spreading COVID-19 infection, $60.3 \%$ agreed that wearing daily disposable contact lenses would reduce the risk of infection, while $60.6 \%$ believe that wearing a frequent replacement contact lens would increase the risk of COVID-19 infection. The same number of practitioners believed that neither hydrogel lenses nor silicone hydrogels $(42.7 \%)$ have any role in COVID-19 infection. Interestingly, 9.8\% of the sample agreed that hydrogel lenses and silicone hydrogel lenses increase the risk of infection with COVID-19.

\subsection{Awareness of Recommended Method of Disinfecting Diagnostic Contact Lenses}

While $28 \%$ of the participants believe that using a hydrogen peroxide-based system should be used to disinfect diagnostic contact lenses, only $8.8 \%$ of the sample believed that using multipurpose solutions is recommended for disinfecting diagnostic contact lenses. Only $5.9 \%$ of the sample identified a multipurpose solution to be a safe medium of soft contact lens storage, while $29.6 \%$ reported using a hydrogen peroxide-based system.

\subsection{ODDs Ratio for Lenses Modality and Workplace- Related Practices - Related Parameters in Relation to Age}

As gender and level of education showed no statistically significant association with any of the perceptions investigated, only age and contact lens practice were included in the multinomial logistic regression analysis. As obtained from Table 1, younger ophthalmologists (30-40 and 41-50 years) were more inclined to believe that using an "air puff" noncontact tonometer increases the chance of getting COVID-19 infection (OR 1.18, 95\% CI: 0.21-6.61, p $<0.01$ and OR 1.62, $95 \%$ CI: $0.27-9.70, p<0.01)$. Practitioners were significantly more likely to perceive that using a protective shield installed in a slit lamp decreases the chance of infection if they are in the 30 to 40 years of age group (OR 1.52, 95\% CI: 0.33-6.96, $\mathrm{p}<0.01)$.

Ophthalmologists were significantly more inclined to believe that daily disposable contact lenses could decrease the chance of getting COVID-19 infection if they are in the 30 to 40 years of age group (OR 4.18, 95\% CI: 0.68-25.66). A completely opposite trend is observed when considering frequent replacement contact lenses role in COVID-19 infection, with higher odds observed among ophthalmologists in the age range of 30-40 years (OR 5.13, 95\% CI: 0.97-27.08), believing their use increases the odds of getting infected.

Ophthalmologists were significantly less likely to believe that using daily lenses increases the chance of getting infected if they were contact lens practitioners (OR $0.51,95 \% \mathrm{CI}$ : $0.48-4.78, \mathrm{p}<0.01$ ), while significantly more likely to perceive that frequent replacement contact lens use can increase the infection spread (2.64, 95\% CI: 1.17-5.94, $\mathrm{p}<0.01)$. 
Table 1. Age as a predictive factor for knowledge of the role of workplace practices and contact lenses in increasing the risk of COVID-19 infection.

\begin{tabular}{|c|c|c|c|c|}
\hline \multirow{2}{*}{ ODDs ratio of workplace practice to COVID-19 infection } & \multirow{2}{*}{ Age } & \multirow{2}{*}{ ODDs ratio } & \multicolumn{2}{|c|}{ Confidence Interval (95\%) } \\
\hline & & & Lower & Upper \\
\hline \multirow{4}{*}{ Using an "air puff" non- contact tonometer increases the chance of getting infected } & $30-40$ years & $1.18^{\mathrm{a}}$ & 0.21 & 6.61 \\
\hline & $41-50$ years & $1.62^{\mathrm{a}}$ & 0.27 & 9.70 \\
\hline & $51-60$ years & $0.90^{\mathrm{a}}$ & 0.11 & 7.02 \\
\hline & $>60$ years & * & * & * \\
\hline \multirow{4}{*}{$\begin{array}{l}\text { Using a protective shield installed on slit lamp increases decreases the chance of getting } \\
\text { infected }\end{array}$} & $30-40$ years & $1.52^{\mathrm{a}}$ & 0.33 & 6.96 \\
\hline & $41-50$ years & $1.22^{\mathrm{a}}$ & 0.25 & 6.07 \\
\hline & $51-60$ years & $1.00^{\mathrm{a}}$ & -0.95 & 1.30 \\
\hline & $>60$ years & * & * & * \\
\hline \multirow{4}{*}{ Appointments should be delayed until the country is announced disease-free } & $30-40$ years & $0.85^{\mathrm{a}}$ & 0.07 & 8.97 \\
\hline & $41-50$ years & $0.50^{\mathrm{a}}$ & 0.08 & 3.10 \\
\hline & 51-60 years & $0.52^{\mathrm{a}}$ & 0.06 & 4.09 \\
\hline & $>60$ years & * & $*$ & * \\
\hline \multirow{2}{*}{ ODDs ratio of lens modality to COVID-19 infection } & \multirow{2}{*}{ Age } & \multirow{2}{*}{ ODDs ratio } & \multicolumn{2}{|c|}{ Confidence Interval (95\%) } \\
\hline & & & Lower & Upper \\
\hline \multirow{4}{*}{ Using daily lenses increases decreases the chance of getting infected } & $30-40$ years & $4.18^{\mathrm{a}}$ & 0.68 & 25.66 \\
\hline & $41-50$ years & $1.74^{\mathrm{a}}$ & 0.26 & 11.52 \\
\hline & $51-60$ years & $1.07^{\mathrm{a}}$ & -1.00 & 9.00 \\
\hline & $>60$ years & * & * & * \\
\hline \multirow{4}{*}{ Using frequent replacement contact lenses increases the chance of getting infected } & $30-40$ years & $5.13^{\mathrm{a}}$ & 0.97 & 27.08 \\
\hline & $41-50$ years & $2.40^{\mathrm{a}}$ & 0.43 & 13.55 \\
\hline & $51-60$ years & $1.39^{\mathrm{a}}$ & 0.19 & 9.97 \\
\hline & $>60$ years & * & $*$ & * \\
\hline
\end{tabular}

: reference, a $P<0.01$.

\section{DISCUSSION}

Most of the ophthalmologists who participated in this study were aware of the name of the virus causing COVID-19. On the other hand, less than half of the study sample were aware of the cause of COVID-19, which could be due to the initial research outcomes in this regard [11]. The role of animals in spreading the disease was not well acknowledged among the participants in comparison to other modes which could be attributed to the fact that the role of animals in the transmission of the disease is strived by media and official platforms in comparison to the other modes of transmission [20 - 22].

The onset of common symptoms such as fatigue, fever, myalgia, dry cough, and dyspnea were initially and widely reported among COVID-19 patients, which could contribute to the high level of awareness of ophthalmologists to these symptoms $[20,21]$. Diarrhea and vomiting were not well recognized due to the scarcity of literature available about such symptoms [23, 24]. Such findings were observed among other healthcare providers $[6,25]$. In terms of immunity support, the major immunity-boosting approaches announced by media and official platforms were well recognized by ophthalmologists [17]. However, the role of other approaches, such as Vitamin E $[4,26]$, and vitamin D [27, 28] intake, were less acknowledged as they were not commonly endorsed.

Personal protective measures and workplace safety measures were recognized and practice, which is in agreement with. Measures adopted by ophthalmologists in other countries
$[29,30]$. This could be attributed to the reliance of ophthalmologists on reputable online resources for information related to protective measures in the workplace and following the WHO guidelines [17]. Nevertheless, few participants reported stopped attending work due to its negative economic impact [31,32].

Lack of direct contact with the patient's eyes in noncontact tonometers is expected to reduce the risk of infection, which would justify the perception of some of the ophthalmologists in this study [33,34]. However, air-puffing tonometers are considered a potential source of SARS-CoV-2 aerosol transmission $[35,36]$. Younger ophthalmologists were more aware of the role of air-puffing tonometers, which could be attributed to their late introduction to Sudan, which exposed the younger generation to these tonometers during their residency training. In light of this, it is advocated for ophthalmologists to switch to contact tonometry while using disposable tips [35]. Meanwhile, most ophthalmologists agreed to the possibility of installing shields in slit lamps to reduce the probability of infection through air droplets which is in agreement with available literature [18, 35].

The odds of believing that wearing daily disposable (DD) contact lenses would reduce the risk of COVID-19 infection is increased if the ophthalmologists are in the 30 to 40 years of age group or contact lens practitioners. Younger ophthalmologists in Sudan tend to get involved in contact lens practice and could be more aware of the benefits of DD lenses 
in reducing ocular complications of contact lens wear [37]. Frequent replacement contact lenses were thought to increase of infection, especially among contact lens practicing ophthalmologists, which is not surprising as frequent replacement contact lens wearers would handle the same lens with their hand more frequently and for more than one day, which could increase the risk of infection [12, 38]. Currently, there is no evidence for the role of contact lens material in the spread of coronavirus, which would justify that most of ophthalmologists could not establish such a relation [12,39].

Sudanese ophthalmologists could not agree on the recommended method of disinfection and storage of diagnostic contact lenses, despite the published recommendations of the use of hydrogen peroxide-based contact lens solution for disinfecting trial contact lenses $[21,40]$. Although the majority of the participants believed that there are credible sources of information for ophthalmic practice during the COVID-19 pandemic, perhaps this is not applicable to contact lenses as there were no national or regional guidelines pertaining to contact lens practice during the COVID-19 pandemic [41]. Ophthalmologists would not perhaps worry about the use of trial contact lenses as only essential and urgent eye care is currently recommended [35]. However, with the apparent willingness of ophthalmologists to resume contact lens practice, it is essential to review the available literature on best practice approaches literature [18, 35].

\section{LIMITATIONS}

The willingness of ophthalmologists to respond to an online survey is an inherent limitation of online surveys. Thus this study may not necessarily represent the knowledge and awareness of all practitioners [42]. Prior knowledge of other epidemics would have affected the participants' perception of this study $[43,44]$. In addition, this study did not address the adoption of telemedicine during the lockdown, which has been observed in other countries which could be useful for ophthalmologists in many parts of the world [45].

\section{CONCLUSION}

This study highlighted the need for ophthalmologists to actively seek advice and recommendations about ophthalmic practices and COVID-19. If such guidelines are not available at the national level, such as the case of Sudan, ophthalmologists can have further information from other professional organizations [46, 47]. Although there is little evidence for an ocular route of SARS-CoV-2 infection with an almost negligible incidence of conjunctivitis reported among COVID-19 patients [48, 49], ophthalmologists need to take all necessary precautions in the workplace.

\section{ETHICS APPROVAL AND CONSENT TO PARTI- CIPATE}

This study was approved by the ethical committee of the Faculty of Allied Medical Sciences at Al-Ahliyya Amman University, Amman, Jordan with approval number: AAU-1/6/2019-2020.

\section{HUMAN AND ANIMAL RIGHTS}

No animals were used in this research. All human research procedures were followed in accordance with the ethical standards of the committee responsible for human experimentation (institutional and national), and with the Helsinki Declaration of 1975, as revised in 2013.

\section{CONSENT FOR PUBLICATION}

Participants were free to withdraw from the study at any point, as stated in the electronic consent form that the participants had to read and agree to prior to filling the questionnaire. Participants' personal information was anonymou,s and participation in the online survey was voluntary.

\section{STANDARDS OF REPORTING}

Checklist for Reporting Results of Internet E-Surveys (CHERRIES) was followed.

\section{AVAILABILITY OF DATA AND MATERIALS}

The data is available from the corresponding author [Y.G] upon reasonable request.

\section{FUNDING}

None.

\section{CONFLICT OF INTEREST}

The author declares no conflict, financial or otherwise.

\section{ACKNOWLEDGEMENTS}

The study design has been approved by the Deanship of Scientific Research of Al-Ahliyya Amman University.

\section{REFERENCES}

[1] Castagnoli R, Votto M, Licari A, et al. Severe acute respiratory syndrome coronavirus 2 (SARS-CoV-2) infection in children and adolescents: A systematic review. JAMA Pediatr 2020; 174(9): 882-9. [http://dx.doi.org/10.1001/jamapediatrics.2020.1467] [PMID: 32320004]

[2] Lim LW, Yip LW, Tay HW, et al. Sustainable practice of ophthalmology during COVID-19: challenges and solutions. Graefes Arch Clin Exp Ophthalmol 2020; 258(7): 1427-36.

[http://dx.doi.org/10.1007/s00417-020-04682-z] [PMID: 32314034]

[3] Ciotti M, Angeletti S, Minieri M, et al. COVID-19 Outbreak: An Overview. Chemotherapy 2019; 64(5-6): 215-23. [http://dx.doi.org/10.1159/000507423] [PMID: 32259829]

[4] Wang L, Wang Y, Ye D, Liu Q. Review of the 2019 novel coronavirus (SARS-CoV-2) based on current evidence. Int J Antimicrob Agents 2020; 55(6): 105948 .

[http://dx.doi.org/10.1016/j.ijantimicag.2020.105948]

[PMID: 32201353]

[5] Chen TM, Rui J, Wang QP, Zhao ZY, Cui JA, Yin L. A mathematical model for simulating the phase-based transmissibility of a novel coronavirus. Infect Dis Poverty 2020; 9(1): 24. [http://dx.doi.org/10.1186/s40249-020-00640-3] [PMID: 32111262]

[6] Khader Y, Al Nsour M, Al-Batayneh OB, et al. Dentists' awareness, perception, and attitude regarding COVID-19 and infection control: Cross-sectional study among jordanian dentists. JMIR Public Health Surveill 2020; 6(2): e18798.

[http://dx.doi.org/10.2196/18798] [PMID: 32250959]

[7] Adams JG, Walls RM. Supporting the Health Care Workforce During the COVID-19 Global Epidemic. JAMA 2020; 323(15): 1439-40. [http://dx.doi.org/10.1001/jama.2020.3972] [PMID: 32163102]

[8] Miller JM, Astles R, Baszler T, et al. Guidelines for safe work 
practices in human and animal medical diagnostic laboratories. Recommendations of a CDC-convened, Biosafety Blue Ribbon Panel. MMWR Suppl 2012; 61(1): 1-102 [PMID: 22217667]

[9] Price ADp, Cui Y, Liao L, et al. Is the fit of N95 facial masks effected by disinfection? A study of heat and UV disinfection methods using the OSHA protocol fit test medRxiv 2020. Available from: http://medrxiv.org/lookup/doi/10.1101/2020.04.14.20062810

[10] Elkholy AA, Grant R, Assiri A, Elhakim M, Malik MR, Van Kerkhove MD. MERS-CoV infection among healthcare workers and risk factors for death: Retrospective analysis of all laboratory-confirmed cases reported to WHO from 2012 to 2 June 2018. J Infect Public Health 2020; 13(3): 418-22.

[http://dx.doi.org/10.1016/j.jiph.2019.04.011] [PMID: 31056437]

[11] Adhikari SP, Meng S, Wu YJ, et al. Epidemiology, causes, clinical manifestation and diagnosis, prevention and control of coronavirus disease (COVID-19) during the early outbreak period: a scoping review. Infect Dis Poverty 2020; 9(1): 29. [http://dx.doi.org/10.1186/s40249-020-00646-x] [PMID: 32183901]

[12] Jones L, Walsh K, Willcox M, Morgan P, Nichols J. The COVID-19 pandemic: Important considerations for contact lens practitioners. Cont Lens Anterior Eye 2020; 43(3): 196-203.

[http://dx.doi.org/10.1016/j.clae.2020.03.012] [PMID: 32273245]

[13] Romano MR, Montericcio A, Montalbano C, et al. Facing COVID-19 in ophthalmology department. Curr Eye Res 2020; 45(6): 653-8. [http://dx.doi.org/10.1080/02713683.2020.1752737] [PMID: 32253942]

[14] Borrelli E, Sacconi R, Querques L, et al. Taking the right measures to control COVID-19 in ophthalmology: the experience of a tertiary eye care referral center in Italy. Eye (Lond) 2020; 34(7): 1175-6. [http://dx.doi.org/10.1038/s41433-020-0880-6] [PMID: 32291402]

[15] Shabto JM, De Moraes CG, Cioffi GA, Liebmann JM. Review of hygiene and disinfection recommendations for outpatient glaucoma care: A COVID era update. J Glaucoma 2020; 29(6): 409-16.

[http://dx.doi.org/10.1097/IJG.0000000000001540] [PMID: 32332334]

[16] GRANMO. Sample size and power calculator 2012. Available from: https://www.imim.cat/ofertadeserveis/software-public/granmo/

[17] WHO. WHO Situation reports - Coronavirus disease 20192020. Available from: https://www.who.int/emergencies/diseases/novel-coronavirus-2019/sit uation-reports

[18] Zeri F, Naroo SA. Contact lens practice in the time of COVID-19. Cont Lens Anterior Eye 2020; 43(3): 193-5. [http://dx.doi.org/10.1016/j.clae.2020.03.007] [PMID: 32201054]

[19] Bryson GL, Turgeon AF, Choi PT. La science de l'opinion: Les méthodes d'enquete dans le domaine de la recherche. Can J Anaesth 2012; 59(8): 736-42.

[http://dx.doi.org/10.1007/s12630-012-9727-3] [PMID: 22610750]

[20] Gorman A. COVID-19 symtoms. New Sci 2020; 246(3280): 56. [http://dx.doi.org/10.1016/S0262-4079(20)30873-3]

[21] CDC. Symptoms of Coronavirus (COVID-19) 2019. Available from: https://www.who.int/emergencies/diseases/novel-coronavirus-2019/qu estion-and-answers-hub/q-a-detail/q-a-coronaviruses

[22] Tiwari R, Dhama K, Sharun K, et al. COVID-19: animals, veterinary and zoonotic links. Vet Q 2020; 40(1): 169-82. [http://dx.doi.org/10.1080/01652176.2020.1766725] [PMID: 32393111]

[23] Rothan HA, Byrareddy SN. The epidemiology and pathogenesis of coronavirus disease (COVID-19) outbreak. J Autoimmun 2020; 109: 102433.

[http://dx.doi.org/10.1016/j.jaut.2020.102433] [PMID: 32113704]

[24] Wong SH, Lui RNS, Sung JJY. COVID-19 and the digestive system. J Gastroenterol Hepatol 2020; 35(5): 744-8.

[http://dx.doi.org/10.1111/jgh.15047] [PMID: 32215956]

[25] Karasneh R, Al-Azzam S, Muflih S, Soudah O, Hawamdeh S, Khader Y. Media's effect on shaping knowledge, awareness risk perceptions and communication practices of pandemic COVID-19 among pharmacists. RSAP 2021; 17(1): 1897-902. [PMID: 32340892]

[26] Muscogiuri G, Barrea L, Savastano S, Colao A. Nutritional recommendations for CoVID-19 quarantine. Eur J Clin Nutr 2020; 74(6): $850-1$

[http://dx.doi.org/10.1038/s41430-020-0635-2] [PMID: 32286533]

[27] Grant WB, Lahore H, McDonnell SL, et al. Evidence that vitamin d supplementation could reduce risk of influenza and covid-19 infections and deaths. Nutrients 2020; 12(4): 1-19. [http://dx.doi.org/10.3390/nu12040988] [PMID: 32252338]

[28] Suvarna VR, Mohan V. Vitamin D and its role in Coronavirus disease 2019 (COVID-19). J Diabetol 2020; 11: 71-80.

[29] Olivia Li JP, Shantha J, Wong TY, et al. Preparedness among ophthalmologists: During and beyond the COVID-19 pandemic. Ophthalmology 2020; 127(5): 569-72. [http://dx.doi.org/10.1016/j.ophtha.2020.03.037] [PMID: 32327128]

[30] Nair AG, Gandhi RA, Natarajan S. Effect of COVID-19 related lockdown on ophthalmic practice and patient care in India: Results of a survey. Indian J Ophthalmol 2020; 68(5): 725-30. [http://dx.doi.org/10.4103/ijo.IJO 797 20] [PMID: 32317434]

[31] Baker S, Bloom N, Davis S, Terry S. "COVID-Induced Economic Uncertainty," NBER Working Papers 26983, National Bureau of Economic Research, Inc. 2020. Available from: https://ideas.repec.org/p/nbr/nberwo/26983.html

[32] Fernandes N. Economic effects of coronavirus outbreak (COVID-19) on the world economy. Available at SSRN 3557504. 2020 Mar 22. Available from: https://mediaroom.iese.edu/wp-content/uploads/2020/03/Fernandes-Nu no_20200322-Global-Recession-is-inevitable.pdf [http://dx.doi.org/10.2139/ssrn.3557504]

[33] Lian KY, Napper G, Stapleton FJ, Kiely PM. Infection control guidelines for optometrists 2016. Clin Exp Optom 2017; 100(4): 341-56. [http://dx.doi.org/10.1111/cxo.12544] [PMID: 28597930]

[34] Lai THT, Tang EWH, Chau SKY, Fung KSC, Li KKW. Stepping up infection control measures in ophthalmology during the novel coronavirus outbreak: An experience from Hong Kong. Graefes Arch Clin Exp Ophthalmol 2020; 258(5): 1049-55.

[http://dx.doi.org/10.1007/s00417-020-04641-8] [PMID: 32124000]

[35] Lai CC, Shih TP, Ko WC, Tang HJ, Hsueh PR. Severe acute respiratory syndrome coronavirus 2 (SARS-CoV-2) and coronavirus disease-2019 (COVID-19): The epidemic and the challenges. Int J Antimicrob Agents 2020; 55(3): 105924.

[http://dx.doi.org/10.1016/j.ijantimicag.2020.105924]

[PMID: 32081636]

[36] Anderson EL, Turnham P, Griffin JR, Clarke CC. Consideration of the aerosol transmission for COVID-19 and public health. Risk Anal 2020; 40(5): 902-7.

[http://dx.doi.org/10.1111/risa.13500] [PMID: 32356927]

[37] Chalmers RL, Hickson-Curran SB, Keay L, Gleason WJ, Albright R. Rates of adverse events with hydrogel and silicone hydrogel daily disposable lenses in a large postmarket surveillance registry: The TEMPO Registry. Invest Ophthalmol Vis Sci 2015; 56(1): 654-63. [http://dx.doi.org/10.1167/iovs.14-15582] [PMID: 25574042]

[38] Willcox MDP, Walsh K, Nichols JJ, Morgan PB, Jones LW. The ocular surface, coronaviruses and COVID-19. Clin Exp Optom 2020; 103(4): 418-24.

[http://dx.doi.org/10.1111/cxo.13088] [PMID: 32406140]

[39] Orsborn G. The importance of credible information about contact lens wear during pandemic. Cont Lens Anterior Eye 2020; 43(3): 214-5. [http://dx.doi.org/10.1016/j.clae.2020.04.008] [PMID: 32359969]

[40] AOA. Disinfection of multi-patient contact lenses in the clinical setting 2018; 1-13. Available from: https://www.aoa.org/AOA/Documents/Advocacy/HPI/Disinfection\%2 0of\%20Multipatient $\% 20$ CLs $\% 20$ in $\% 20$ the $\% 20$ Clinical\%20Setting.pd $\mathrm{f}$

[41] MEACO. Middle east and africa council of ophthalmology COVID-19 recommendation $2020 . \quad$ Available from: http://www.icoph.org/downloads/MEACO-COVID-19-Recommendati ons-Arabic.pdf

[42] Bhagavathula AS, Aldhaleei WA, Rahmani J, Mahabadi MA, Bandari DK. Knowledge and perceptions of COVID-19 among health care workers: Cross-sectional study. JMIR Public Health Surveill 2020; 6(2): e19160.

[http://dx.doi.org/10.2196/19160] [PMID: 32320381]

[43] Piltch-Loeb R, Zikmund-Fisher BJ, Shaffer VA, et al. Cross-sectional psychological and demographic associations of zika knowledge and conspiracy beliefs before and after local zika transmission. Risk Anal 2019; 39(12): 2683-93.

[http://dx.doi.org/10.1111/risa.13369] [PMID: 31290166]

[44] Vinck P, Pham PN, Bindu KK, et al. Institutional trust and misinformation in the response to the 2018-19 Ebola outbreak in North Kivu, DR Congo: A population-based survey. The Lancet Infectious Diseases 2019; 19(5): 529-36.

[http://dx.doi.org/10.1016/S1473-3099(19)30063-5] [PMID: 30928435] 
[45] Saleem SM, Pasquale LR, Sidoti PA, Tsai JC. Virtual ophthalmology: Telemedicine in a COVID-19 Era. Am J Ophthalmol 2020; 216: $237-42$.

[http://dx.doi.org/10.1016/j.ajo.2020.04.029] [PMID: 32360862]

[46] International council of ophthalmology. ICO Global COVID-19

Resource Center 2020. Available from: http://www.icoph.org/news/news_detail/602/ICO-Global-COVID-19Resource-Center.html

[47] World Council of Optometry. Tips for reopening your office after
COVID-19 2020. Available from: https://worldcouncilofoptometry.info/covid-19-news/

[48] Wilcox SR. Management of respiratory failure due to covid-19. BMJ 2020; 369: m1786.

[http://dx.doi.org/10.1136/bmj.m1786] [PMID: 32366375]

[49] Docherty AB, Harrison EM, Green CA, et al. Features of 16,749 hospitalised UK patients with COVID-19 using the ISARIC WHO clinical characterisation protocol. medRxiv 2020;2. Available from: https://www.medrxiv.org/content/10.1101/2020.04.23.20076042v1

\section{C) 2021 Yazan Gammoh}

This is an open access article distributed under the terms of the Creative Commons Attribution 4.0 International Public License (CC-BY 4.0), a copy of which is available at: https://creativecommons.org/licenses/by/4.0/legalcode. This license permits unrestricted use, distribution, and reproduction in any medium, provided the original author and source are credited. 